Artigo Original

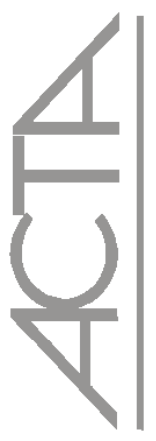

\title{
Readiness for enhanced self-health management among people with diabetes mellitus
}

\author{
Disposição para controle aumentado do regime terapêutico entre pessoas com diabetes mellitus
}

Disposición para el control aumentado del régimen terapéutico entre personas con diabetes mellitus

\begin{abstract}
Márcio Flávio Moura de Araújo ${ }^{1}$, Ana Maria Parente Garcia Alencar ${ }^{2}$, Thiago Moura de Araújo $^{3}$, Marta Maria Coelho Damasceno ${ }^{4}$, Joselany Áfio Caetano ${ }^{5}$ Lorena Barbosa Ximenes ${ }^{6}$, Neiva Francenely da Cunha Viera ${ }^{7}$
\end{abstract}

\begin{abstract}
Objective: To identify the nursing diagnosis, readiness for enhanced self-health management, among people with type 2 diabetes who are adherent to pharmacological treatment. Methods: The sample consisted of 579 subjects from 12 primary care services who received home visits. To determine adherence to the pharmacological treatment, the pill count test was conducted. Those classified as adherent were given a checklist with the defining characteristics of the nursing diagnosis, readiness for enbanced self-health management. Results: Subjects with type 2 diabetes who presented with the nursing diagnosis were not alcoholics $(p=0.003)$, did not miss their diabetes consultations $(p=0.000)$, and had no difficulties / inappropriate behaviors with regard to taking their oral antidiabetic agents $(p=0.000)$. Conclusion: The identification of human responses to the clinical treatment of type 2 diabetes should be continuous, so that nurses can understand the factors involved in the readiness to enhance therapeutic control.
\end{abstract}

Keywords: Diabetes mellitus, type 2; Patient compliance; Nursing diagnosis; Health promotion.

\section{RESUMO}

Objetivo: identificar o diagnóstico de enfermagem disposição para controle aumentado do regime terapêutico entre pessoas com diabetes tipo 2 aderentes ao tratamento farmacológico. Métodos: A amostra foi constituída de 579 sujeitos de 12 serviços de atenção primária que receberam visitas domiciliares. Para determinar a adesão ao tratamento farmacológico foi realizado o teste da contagem de comprimidos. Naqueles classificados como aderentes foi aplicado um check list com as características definidoras do diagnóstico de enfermagem disposição para controle aumentado do regime terapêutico. Resultados: Os sujeitos com DM 2 que apresentaram o diagnóstico de enfermagem estudado não eram etilistas ( $\mathrm{p}=0,003)$, não faltavam as consultas para DM $2(\mathrm{p}=0,000)$ e não tinham dificuldades/comportamentos inadequados na tomada dos antidiabéticos orais $(\mathrm{p}=0,000)$. Conclusão: A identificação de respostas humanas frente ao tratamento clínico dos sujeitos com diabetes tipo 2 deve ser contínua para que o enfermeiro possa conhecer os fatores envolvidos numa disposição aumentada para o controle terapêutico.

Descritores: Diabetes mellitus tipo 2; Cooperação do paciente; Diagnóstico de enfermagem; Promoção da saúde

\section{RESUMEN}

Objetivo: identificar el diagnóstico de enfermería disposición para el control aumentado del régimen terapéutico entre personas con diabetes tipo 2 adheridas al tratamiento farmacológico. Métodos: La muestra estuvo constituida por 579 sujetos de 12 servicios de atención primaria que recibieron visitas domiciliarias. Para determinar la adhesión al tratamiento farmacológico fue realizado el test del recuento de comprimidos. En aquellos clasificados como adherentes se aplicó un check list con las características definidoras del diagnóstico de enfermería disposición para el control aumentado del régimen terapéutico. Resultados: Los sujetos con DM 2 que presentaron el diagnóstico de enfermería estudiado no eran etílicos ( $\mathrm{p}=0,003)$, no faltaban a las consultas para DM $2(\mathrm{p}=0,000)$ y no tenían dificultades/comportamientos inadecuados en la toma de los antidiabéticos orales ( $\mathrm{p}=0,000)$. Conclusión: La identificación de respuestas humanas frente al tratamiento clínico de los sujetos con diabetes tipo 2 debe ser continua para que el enfermero pueda conocer los factores involucrados en una disposición aumentada para el control terapéutico.

Descriptores: Diabetes mellitus tipo 2; Cooperación del paciente; Diagnóstico de enfermería; Promoción de la salud

\footnotetext{
${ }^{1}$ Pós-graduando (Doutorado) do Programa de Pós-Graduação em Enfermagem da Universidade Federal do Ceará - UFC - Fortaleza (CE), Brasil.

${ }^{2}$ Pós-graduando (Doutorado) do Programa de Pós-Graduação em Enfermagem da Universidade Federal do Ceará - UFC - Fortaleza (CE), Brasil.

${ }^{3}$ Pós-graduando (Doutorado) do Programa de Pós-Graduação em Enfermagem da Universidade Federal do Ceará - UFC - Fortalez̧a (CE), Brasil.

${ }^{4}$ Pós-Doutora em Enfermagem. Professora do Programa de Pós-Graduação em Enfermagem da Universidade Federal do Ceará - UFC - Fortaleza (CE), Brasil.

${ }^{5}$ Doutora em Enfermagem. Professora do Programa de Pós-Graduação em Enfermagem da Universidade Federal do Ceará - UFC - Fortaleza (CE), Brasil.

${ }^{6}$ Doutora em Enfermagem. Professora do Programa de Pós-Graduação em Enfermagem da Universidade Federal do Ceará - UFC - Fortaleza (CE), Brasil.

${ }^{7}$ PhD pela Bristol University. Professora do Programa de Pós-Graduação em Enfermagem da Universidade Federal do Ceará - UFC - Fortaleza (CE), Brasil.
} 


\section{INTRODUCTION}

Given the globalization of diverse health problems, the actions of health education and international health promotion are greatly impacting the dissemination of knowledge so that abilities, skills and attitudes for tackling global health problems such as HIV/Aids, malaria, cardiovascular disease and type 2 diabetes mellitus (type 2 DM). In much of Europe, North America and Australia this fact is already a reality. In countries such as Spain, Holland, Japan, Israel, China, India and Taiwan there is a growing movement with regard to these actions. Conversely, in Africa, Latin America and Asia Pacific these health promotion actions need to be improved. ${ }^{(1)}$

In Latin America, for example, health education of patients with type $2 \mathrm{DM}$ has been largely ignored, with less than $20 \%$ of these clients having access to this therapeutic modality. ${ }^{(2)}$ In Brazil, the situation is similar, which may explain the fact that consistently throughout the country, less than $8 \%$ of subjects with type $2 \mathrm{DM}$ in primary healthcare present health-promoting behavior. ${ }^{(3)}$ However, the policies of primary healthcare and health promotion in Brazil have given particular attention to the different levels of prevention of type 2 DM. Above all, secondary prevention when pathology already exists has given rise to debate, with the literature demonstrating the importance of health promotion actions to achieve the effective management of type $2 \mathrm{DM}$ and the empowerment of these subjects directed toward their quality of life. ${ }^{(4,5)}$

The Pan American Health Organization (PAHO) and the World Health Organization (WHO) affirm that among the essential skills for primary healthcare professionals is the ability to identify and analyze barriers to access/adherence and actors involved in the health problems $\left.{ }^{(}\right)$. In the same way, Jackson (2007) proposes that the key attribute for nurses to trigger health promotion in the community is their ability to detect the needs of the subjects at the individual and group level, followed by decision making and cooperative work. In congruence with that reported by the PAHO, the WHO and Jackson (2007), NANDA International (2008) affirms that nurses are professionals with the capacity to diagnose potential or actual experiences/human responses related to the health-disease continuum and life processes. ${ }^{(7-8)}$ Given the above statements, it is clear that to diagnose responses is an important health promotion action within the arsenal of existing possibilities and that the nurse can be active in this process in primary healthcare, especially among subjects with type $2 \mathrm{DM}$.

Previously, studies published in Brazil and abroad about nursing diagnoses in diabetic patients have provided generalized information on risks, including the association of sociodemographic characteristics and/or clinics. ${ }^{(8-10)}$ Within this perspective, NANDA International (NANDA-I) has identified diagnoses for health promotion, which consist of a clinical judgment of motivation and the desire of a person, family or community to increase well-being through changes in specific health behavior. These diagnoses can be used in any state of health and do not require current levels of well-being. ${ }^{8}$

Within the problem of adherence to pharmacological treatment for type $2 \mathrm{DM}$, the health promotion nursing diagnosis that is most adequate for the patient to effectively adhere to pharmacological treatment with oral antidiabetic agents $(\mathrm{OA})$ is: readiness for enhanced therapeutic regimen management. ${ }^{(8)}$ Although other factors are relevant, for the professionals who care for people with type $2 \mathrm{DM}$, the compliance with OA therapy is a key strategy in the metabolic control of this disease over time..$^{(1,11)}$

Nurse researchers believe it to be important that studies be undertaken regarding the association between nursing diagnoses and the determined characteristics of the study group. This belief is based on the benefits arising from the previously mentioned studies, including, the deepening of the knowledge concerning risk factors and characteristics related to the problem in question. ${ }^{(7)}$ Furthermore, the prevalence of health promotion nursing diagnoses and their characteristics with regard to people with diabetes is still unknown. Thus, the aim of this study was to identify the nursing diagnosis, Readiness for enhanced therapeutic regimen management, among Brazilians with type $2 \mathrm{DM}$ who are compliant with $\mathrm{OA}$ treatment in the primary healthcare services.

\section{METHODS}

This was a cross-sectional study conducted from January to July 2009, in 12 primary health units located in Fortaleza - Brazil. The metropolis of Fortaleza, located in northeastern Brazil, is divided into six regions to facilitate the administration by the organizations responsible, and had 173,000 diabetics registered in the primary healthcare system in 2008. To obtain representative data for Readiness for enhanced therapeutic regimen management among subjects with type $2 \mathrm{DM}$ in the city studied, two services of primary care in diabetes were chosen from each region, located in neighborhoods which differed with regard to the infrastructure, services and socioeconomic status of the residents.

The sample was distributed by clusters and, for the calculation, a formula for infinite populations was used. Furthermore, the indicator compliance with pharmacological therapy by diabetics in primary healthcare was chosen as the outcome. This is because it was not possible to find publications that had measured the nursing diagnosis in question. The prevalence adopted of this item was $45.5 \%$, ${ }^{(12)}$ the significance level and sampling error were $\alpha=0.05$ and $5 \%$ respectively. The initial sample size was 406 . However, due to a 10\% loss rate, which included rejections, hospitalizations, withdrawals, and subjects with erroneous and/or missing information, the final sample size for analysis was 369 type 2 diabetics. 
The study subjects were selected using a non-probability method within each health service, provided they met the following inclusion criteria: a confirmed diagnosis of type $2 \mathrm{DM}$; received care in one of the primary healthcare networks selected for the study; lived in Fortaleza (Brazil) and had a contact number; were treated for at least six months with the same prescription; had a medical record or health form available at the service; and, were compliant with the pharmacological OA therapy. The exclusion criteria established were: hospitalized during data collection period; total dependence on others for self-care activities; and, unable to respond to interview questions.

For the data collection a questionnaire was constructed dealing with sociodemographic, clinical and medication data. In addition, an instrument in the form of a check list was designed, containing the five defining characteristics of the referred diagnosis, conforming to the NANDA-I version 2009-2011. This check list was evaluated by three doctorally-prepared nurse researchers in order to confirm its applicability. Data were collected between March and July 2009 in the 12 selected services on the days related to consultation for patients with type $2 \mathrm{DM}$, as patients waited to receive their medication from the pharmacies of the health units. On this occasion and after consenting to participate, the sociodemographic and clinical data were collected, together with data regarding the treatment of type $2 \mathrm{DM}$, their complete address and telephone number. Finally, participants were given a plastic bag and were instructed to place the OA received from the pharmacy that day into that bag, and to use only these pills during the study, even if they had other pills at home.

The information from this data collection was compared with that of the medical records and/or health forms in order to ascertain its veracity. Following this, the inclusion and exclusion criteria were applied to the subjects in order to select those eligible. Ten days after the above phase the selected subjects received a surprise visit at their respective domiciles, at which time interviews were conducted and the check list of the defining characteristics was applied.

To determine whether the subjects had been adherent to the pharmacological therapy with $\mathrm{OA}$, the pill count test (PCT) was performed in the subjects' homes, from the plastic bag given previously in the health units. Among the indirect methods of medication adherence measurement, this strategy is considered the gold standard. Medication compliance was considered from the percentage obtained between the ratio of the number of OA taken and the number of OA prescribed. The percentages were interpreted as follows: between $80 \%-110 \%$ Good compliance, $<80 \%$, Hypocompliance; $>110 \%$ Hypercompliance. Finally, the Hypocompliant and Hypercompliant subjects were classified as not adhering to the pharmacological therapy..$^{(13)}$

The defining characteristic reduction of risk factors was considered present in those who presented with adequate nutrition, appropriate alcohol use and smoking status according to the recommendations of the Brazilian Diabetes Society (2009). The characteristic, choices of daily living are adequate for meeting the goals of prevention, was considered present in those who practiced planned physical activities between three to five times per week and followed a balanced diet regarding the intake of sugars and fats. ${ }^{(14-15)}$ The characteristic, expresses desire to manage the treatment of illness, was determined from the frequency of the patients keeping scheduled consultations for the treatment of type $2 \mathrm{DM}$ in the unit. The characteristic, expresses little difficulty with the prescribed therapeutic regimen, was considered present in subjects in whom adherence to pharmacologic treatment was evident. The Measurement of Treatment Adherence (MTA) test was validated, translated and adapted into Portuguese. ${ }^{16}$

The characteristic, no unexpected acceleration of illness symptoms, was detectable from the glycemia value being within acceptable limits. During the home visit, this sign was measured using a glucometer and the respective test strip of the trademark Optium ${ }^{\circledR}$. The detected values were evaluated based upon the fasting or postprandial state of the subjects. ${ }^{(17)}$

In order to accurately determine nursing diagnoses based upon the findings, a consensus by three master's-prepared nurses focused on health promotion was obtained after the home visits. The data were double entered, tabulated and stored in a database using the software Epi-info version 6.04. Measures of central tendency were calculated and the confidence interval of $95 \%$ adopted. In the analysis of the associations of the defining characteristics related to the diagnosis, readiness for enhanced therapeutic regimen management, with selected categorical variables, Fisher's exact test was used. Bartlett's test was employed for the evaluation of normality of the variables.

The project was submitted to the Research Ethics Committee of the Center for Health Sciences of the Federal University of Ceará - Brazil and was approved according to protocol 47/09.

\section{RESULTS}

In total 579 subjects were evaluated in the 12 primary healthcare units. There was greater participation of women $(70.3 \%)$, Caucasians $(48.1 \%)$ and mixed race (34.8\%) individuals. Subjects were between 18 and 92 years of age, divided into the following age groups: $18-59$ years $(41.1 \%), 60-69$ years $(29.5 \%), 70-79$ years $(20.1 \%)$ and $80-92$ years $(9.3 \%)$. The mean age and years of study were 63.1 years $(S D \pm 11.6)$ and 4.3 years $(\mathrm{SD} \pm 3.7)$, respectively. Slightly more than half $(55.8 \%)$ of the subjects investigated were married or lived in a stable consensual relationship, while the minority $(6.9 \%)$ were single. A substantial proportion owned their own house $(84.9 \%)$ and approximately half of the subjects 
studied (45.8\%) lived in a nuclear family composed of a partner, children and/or grandchildren. Most were retired $(49.4 \%)$ and this source of income was the main form of support for the offspring of the subjects $(48.7 \%)$. There was a predominance of economic classes $\mathrm{D}$ and $\mathrm{C}$, with low purchasing power by Brazilian standards. The mean monthly family income was US\$445.9 (SD \pm 327.1 ).

Regarding the taking of OA, $76 \%$ of the subjects claimed not to need help from relatives to remind them when it was time to take the medication. Of the subjects that needed assistance, in $12.8 \%$ of cases the person who helped was their child or grandchild. One interesting point to emphasize is that although $90.6 \%$ of the subjects referred to having received guidance from the physician or nurse about taking OA, approximately 15\% did not understand this, favoring the incorrect use of these drugs. A point of concern is that $43.5 \%$ of the subjects had been prescribed two classes of medication per day. The main OA used were metformin $(22.9 \%)$, glibenclamide $(21.5 \%)$ and the combination of these (43.5\%), with a mean of $3.0(\mathrm{SD} \pm 1.7)$ pills taken daily. Despite the results of the MTA test, which indicated that $62 \%$ of the interviewees had never interrupted the pharmacological therapy for type $2 \mathrm{DM}$ due to lack of medication, during the home visits it was observed that $10.6 \%$ had stopped treatment due to lack of anti-diabetic agents. In these cases, the absent drug was glibenclamide. Among the study sample, only $15.1 \%(\mathrm{~N}=88)$ were classified as compliant with the OA pharmacological treatment. In each of these subjects the diagnosis of readiness for enhanced therapeutic regimen management was detected.

Only one defining characteristic, choices of daily living are adequate for meeting the goals of prevention, presented no statistically relevant item. From the interpretation of the findings of the other defining characteristics, it was possible to determine that the subjects with type $2 \mathrm{DM}$ who presented the diagnosis studied were not alcohol users $(p=0.003)$, did not miss consultations for type $2 \mathrm{DM}(\mathrm{p}=0.000)$ and had no difficulties/inadequate behavior in the taking of the $\mathrm{OA}$ $(\mathrm{p}=0.000)$. In turn, among the patients who had the nursing diagnosis in question, the glycemia measurement was predominantly classified as elevated $(\mathrm{p}=0.022)$ (Table 1$)$.

Furthermore, regarding the taking of medication, independent of the results of the adhesion methods explored, it was observed that $10.6 \%$ of the subjects were using violated pill cards, in some cases with expired validity dates, and abandoned treatment. A smaller proportion, $9.7 \%$, used anti-diabetics only when they remembered and the other, $6.2 \%$ took less than indicated because of confusion with the prescribed dose (Table 2).

\section{DISCUSSION}

Previous Brazilian publications identified similar sociodemographic data to this study with a predomination of females, Caucasians and subjects who were married, and/or living in a stable, consensual relationship. ${ }^{(10,12,18)}$

In relation to the defining characteristics of the diagnosis in question, the characteristic, reduction of risk factors, identified that adherent diabetics did not use alcohol, and to a statistically significant degree found that poor therapeutic adherence of diabetics was associated with a history of alcohol use. ${ }^{(19)}$ A similar phenomenon was also reported by a researcher who evaluated 65,996 adults with type $2 \mathrm{DM}$ and verified that the risk of poor adherence to self-care increased proportionately with the amount of alcohol intake reported by the patient. ${ }^{(20)}$

The Brazilian Diabetes Society and the American Diabetes Association recommend that health professionals should identify the use of alcohol and tobacco among diabetic patients monitored in health services and institute educational guidelines that may encourage the abandonment of these practices, due to their contribution to the micro and macrovascular complications of endocrinopathy. ${ }^{(14-15)}$ Moreover, as noted by other authors, the health team should make efforts to achieve the goal of reducing morbidity conditions that predispose individuals to increased complications in type $2 \mathrm{DM} .{ }^{(12)}$ As argued by researchers, these complications can be prevented and/or delayed if people with diabetes exhibit good adherence to dietary and therapeutic medication regimes, in addition to regular exercise and glycemic monitoring. ${ }^{(5,21-22)}$

It became evident that the majority of subjects with this nursing diagnosis did not miss their health care consultations, and therefore they met the characteristic, expresses desire to manage the treatment of the illness. Type 2 $\mathrm{DM}$ is a chronic disease that requires continuous and systematic monitoring, and necessitates examinations and delivery of continuous medications. Since the majority of the subjects had low purchasing power, it is possible that the availability of free medication was a factor that favored the participation of the clients in the scheduled consultations. ${ }^{(21)}$ In this sense, the effective attendance of the diabetics at the consultations must be seen not only as an action that promotes their adherence to medication treatment, it is also a critical for patients to interact with the health care team, allowing them to be participatory agents in the care process as they contribute to the planning of health-promoting activities. When the patient is unable to attend the unit it is necessary to conduct continuous home visits which, in addition to the interaction, may provide the opportunity to gain knowledge of the environment in which the subject with type $2 \mathrm{DM}$ lives.

Given the chronic nature of type $2 \mathrm{DM}$ it is essential that diabetics have the correct answers to their questions about the clinical management of their illness. In addition to strengthening the therapeutic relationship, this could result in a decreased level of uncertainty. The higher the level of uncertainty about the disease in relation to the 
Table 1. Association between the defining characteristics of the diagnosis Readiness for enhanced therapeutic regimen management and the compliance with medicinal treatment among Brazilians with type 2 DM. Fortaleza, Brazil, 2009

\begin{tabular}{|c|c|c|c|c|}
\hline Defining characteristics & f & $\%$ & & p-value $*$ \\
\hline \multicolumn{5}{|c|}{ Describes reduction of risk factors } \\
\hline \multicolumn{5}{|l|}{$\mathrm{BMI} * *$} \\
\hline Normal & 27 & 32.9 & $\mathrm{MD}=25.4 \mathrm{~kg} / \mathrm{m} 2$ & 0.339 \\
\hline Elevated & 54 & 65.9 & $\mathrm{SD} \pm 8.5$ & \\
\hline \multicolumn{5}{|l|}{ Alcohol user } \\
\hline Yes & 03 & 3.4 & & \\
\hline No & 85 & 96.6 & & 0.003 \\
\hline \multicolumn{5}{|l|}{ Smoker } \\
\hline Yes & 14 & 15.9 & & 0.488 \\
\hline No & 74 & 84.1 & & \\
\hline \multicolumn{5}{|c|}{ Choices of daily living appropriate to meet goals } \\
\hline \multicolumn{5}{|c|}{ Practice of physical activity } \\
\hline Active & 23 & 26.1 & & 0.380 \\
\hline Sedentary & 65 & 73.9 & & \\
\hline \multicolumn{5}{|l|}{ Adequate diet } \\
\hline Yes & 79 & 89.7 & & 0.091 \\
\hline No & 09 & 10.3 & & \\
\hline \multicolumn{5}{|c|}{ Expressed desire to manage disease } \\
\hline \multicolumn{5}{|c|}{ Misses consultations of the unit } \\
\hline No & 71 & 80.6 & $\mathrm{MD}=0.2$ & 0.000 \\
\hline Yes & 17 & 19.4 & $\mathrm{SD} \pm 0.5$ & \\
\hline \multicolumn{5}{|c|}{ Expressed little difficulty with the prescribed treatment regimen } \\
\hline Yes & 38 & 63.3 & & 0.000 \\
\hline No & 22 & 36.7 & & \\
\hline \multicolumn{5}{|c|}{ No unexpected acceleration of illness symptoms } \\
\hline \multicolumn{5}{|l|}{ Glycemia } \\
\hline Normal & 23 & 38.3 & $\mathrm{MD}=191.8 \mathrm{mg} / \mathrm{dl}$ & 0.022 \\
\hline Elevated & 37 & 61.7 & $\mathrm{SD} \pm 96.6 \mathrm{mmHg}$ & \\
\hline
\end{tabular}

*Fisher's test $\quad * *$ patients who responded

Table 2. Distribution of problems identified in taking oral anti-diabetics according to the field diary. Fortaleza-Brazil, 2009

\begin{tabular}{lcc}
\hline Problems identified & $\mathbf{\%}$ & $\mathbf{C I} \mathbf{- 9 5 \%}$ \\
\hline Abandoned the treatment & 10.6 & $5.6-17.8$ \\
Absence of medication & 1.8 & $0.2-6.2$ \\
Cards violated & 10.6 & $5.6-17.8$ \\
Sharing of medication with diabetic spouse & 9.7 & $5.0-16.8$ \\
Sharing of cards between users with type 2 DM & 11.5 & $6.3-18.9$ \\
Large number of pills for the prescription & 26.5 & $18.7-35.7$ \\
Do not believe in the disease & 0.9 & $0.0-4.8$ \\
Stopped treatment due to lack of medication & 10.6 & $5.6-17.8$ \\
Takes less medication than prescribed & 6.2 & $1.7-16.2$ \\
Uses only when remembered & 9.7 & $5.0-16.8$ \\
Use of alternating cards & 1.8 & $0.2-6.2$ \\
\hline Total & 100.0 & \\
\hline
\end{tabular}

CI-Confidence interval 
diagnosis and treatment, the less diabetics feel motivated to adopt a healthy lifestyle, regarding the medication treatment, glycemic control and the practice of physical exercise. Inadequate metabolic control of patients with type $2 \mathrm{DM}$ can be reduced by $80 \%$ through health education. ${ }^{(23)}$ Another important aspect to consider is the quality of healthcare dispensed to the patient with type $2 \mathrm{DM}$. There is evidence that when therapeutic measures are conducted by health professionals that are specialists in the area of diabetes mellitus there is a greater impact than when they are performed by generalists, including increased physical exercise, smoking and alcohol reduction, and the correct use of insulin..$^{(24-25)}$

Research has shown that diabetic patients adhering to therapeutic measures and self-care, who were subsequently trained through empowerment sessions, could acted as a bridge between health professionals and the diabetic patients in the community who did not adhere to treatment. The contact by these empowered DM patients with nonadherent diabetic patients in the community was found to decrease abandonment/lack of commitment with therapy from $28.6 \%$ to $6.5 \%$, and unsatisfactory glycemic control from $18.2 \%$ to $10.8 \%$ for up to three years. ${ }^{(26)}$

Regarding the defining characteristic, expresses little difficulty with the treatment regime, the majority of the subjects reported having little difficulty in managing the prescribed treatment. This result was not observed in previous publications on this theme..$^{(12,27-28)}$ Although the studies presented little difficulty with the prescribed regimen, the consensus among health professionals was that this aspect is still a problem to be overcome among diabetics, in the face of the chronicity of this disease. Moreover, even with the realization that the majority of patients do not have any difficulties in the clinical management of type $2 \mathrm{DM}$, a large proportion of the subjects of the present study had glycemic values above the recommended.

In this study glycemia was used as a proxy for the defining characteristic, no unexpected acceleration of illness symptoms, where poor glycemic control among the majority of the subjects became evident. In the literature there is already a consensus, among specialists in type 2 $\mathrm{DM}$, that rigorous control prevents the onset of micro and macrovascular complications. However, it is possible to encounter some studies with results opposite to the present study, adopting both the glycated hemoglobin (HbA1c) as well as the capillary casual. ${ }^{(18,29-30)}$ Given these findings, it is possible that other health-promoting behaviors, such as the practice of regular physical exercise and balanced diet, are more significant predictors of the glycemic level and of the appearance of complications than the correct taking of OA.

In Brazil, primary healthcare users with type $2 \mathrm{DM}$, rarely perform health-promoting behaviors. ${ }^{(3)}$ For people living with type $2 \mathrm{DM}$, health promotion actions should go beyond encouragement to take medications correctly; these actions should seek to maintain the individual's productivity and work potential, and the roles already established in the family and social environment prior to the disease condition; there must be a harmonious coexistence of the limitations imposed by the disease and healthy living. (14) Individuals with type $2 \mathrm{DM}$ participating in health programs should be perceived to have active lives, and most importantly to be responsible for their care in relation to their illness. This means that they need to be motivated, that is, internally driven to seek the promotion of their health. To achieve this goal it is critical that nurses carefully consider their health promoting activities. Thus, beyond the framework constructed around competencies, skills, and attitudes, another ability required of health promoting nurses is reflective practice. This is a big step in the direction of conscious, reflective practice toward the empowerment of health professionals and subjects with type $2 \mathrm{DM}$.

\section{CONCLUSIONS}

This article presented weaknesses in the collection of the nursing diagnosis studied. First, a nursing assessment was not performed for the data collection. Self-reported data were used in the measurement of BMI, which leads to a greater probability of underestimation of body weight. Furthermore, in the evaluation of glycemia it was not possible to perform more accurate examination such as HbA1c. Strengths of the study include the fact that a representative sample of the Brazilian city in question was used, and the originality of the study in the national and international scenario should be mentioned.

In the panorama of primary healthcare, the identification of human responses of the subjects with type $2 \mathrm{DM}$ to the clinical treatment should be continuous so that the nurse can comprehend the factors involved in an increased readiness for enhanced therapeutic regimen management, to identify characteristics that can be disseminated among other diabetic patients through health promotion practices.

Nurses contribute to the issue of health promotion of people with type $2 \mathrm{DM}$ through reflective nursing practice that can occur through the sharing of information and experiences. This can provide a moment in which new information is discovered, and gaps, needs and solutions to problems can be identified. Finally, conducting home visits with type $2 \mathrm{DM}$ individuals who adhere to medication treatment can be an initial step in understanding the family, it's socioeconomic and cultural scenario, and the support networks involved in correctly taking the OA. This may also encourage those patients to share their experiences with other diabetics. The healthcare provided to patients with diabetes mellitus has a large influence on their self-care practices and in the control of endocrinopathy by the patients. 


\section{REFERENCES}

1. Allegrante JP, Barry MM, Airhihenbuwa CO, Auid MA, Collins JL, Lamarre CM. Domains of core competency, standards, and quality assurance for building global capacity in health promotion: The Galway Consensus Conference statement. Health Educ Behav. 2009; 36(3): 476-82.

2. Stewart GL, Tambascia M, Guzmán JR, Etchegoyen F, Carrión JO, Artemenko S. Control of type 2 diabetes in private practice in nine countries of Latin America. Rev Panam Salud Publica. 2007; 22(1):12-20.

3. Sampaio FA, Melo RP, Rolim IL, Siqueira RC, Ximenes LB, Lopes MV. Evaluation of the health promotion behavior in patients with diabetes mellitus. Acta Paul Enferm. 2008; 21(1), 84-8.

4. Brasil. Ministério da Saúde. Secretaria de Atenção à Saúde. Caderno de Atenção Básica-Diabetes Mellitus. Brasília(DF): Ministério da Saúde; 2006.

5. Araújo MF, Damasceno MM. La adhesión del diabético al tratamiento farmacológico com hipoglicemiantes orales: uma investigación bibliográfica. Rev Enfermería Integral. 2008; 84: 68-73.

6. Adell CN, Echevarria CR, Bentz RMB. Development of primary health care competencies. Pan Am J Public Health. 2009; 26(2): 176-83.

7. Jackson L. Promotion health for communities. In: Willes, J. Vital notes for nurses- Promotion Health. London: WileyBlackwell; 2007.

8. Herdman TH, editor. Diagnósticos de enfermagem da NANDA: definições e classificação (2009-2011). Porto Alegre: Artmed; 2010.

9. Vasconcelos FF, Araújo TL, Moreira TM, Lopes MV. Association among nursing diagnoses, demographic variables, and clinical characteristics of patients with high blood pressure. Acta Paul Enferm. 2007; 20(3):326-32.

10. Milhomem AC, Mantelli FF, Lima GAV, Bachion MM, Munari DB. Diagnósticos de enfermagem identificados em pessoas com diabetes tipo 2 mediante abordagem baseada no Modelo de Orem. Rev Eletr Enferm. 2008; 10(2): 321-36.

11. García-Pérez AM, Leiva Fernandez F, Martos Crespo F, García Ruiz AJ, Prados Torres D, Sánchez C, et al ¿Como diagnosticar el cumplimiento terapêutico en atención primaria? Med Família (And). 2000; 1(1): 13-9.

12. Araújo MF, Gonçalves TC, Damasceno MM, Caetano JA. Adherence of diabetics patient to pharmacological treatment with oral hypoglycemic agents. Esc Anna Nery. 2010; 14(2), 361-7.

13. Sackett DL, Haynes RB, Gibson ES. Randomised clinical trial of strategies for improving medicacion compliance in primary hypertension. Lancet. 1975; 1: 1205-7.

14. Sociedade Brasileira de Diabetes. Atualização sobre Diabetes. Sociedade Brasileira de Diabetes. Rio de Janeiro: Diagraphic;. 2009.

15. American Diabetes Association (ADA). Standards of Medical Care in Diabetes-2007. Diabetes Care. 2007; 30 (Suppl. 1): S4 - S41.

16. Delgado AB, Lima ML. Contributo para a validação concorrente de uma medida de adesão aos tratamentos. Psicol Saúde Doenças. 2001; 2(2): 81-100.
17. Pascali PM. Monitorização da glicemia. In: Grossi, SAA, Pascali PM, organizadores. Cuidados de enfermagem em diabetes mellitus. São Paulo: Sociedade Brasileira de Diabetes; 2009.p.41-55.

18. Silva I, JP Ribeiro, H Cardoso. Adesão ao tratamento da diabetes mellitus: a importância das características demográficas e clínicas. Rev Referência. 2006; 11(2):33-41.

19. Mendes TD, Goldbaum M, Segri NJ, Barros MB, Cesar CL, Carandina L, et al. Diabetes mellitus: factors associated with prevalence in the elderly, control measures and practices, and health services utilization in São Paulo, Brazil. Cad Saude Publica. 2011; 27(6):1233-43.

20. Ahmed AT, Karter AJ, Liu J. Alcohol consumption is inversely associated with adherence to diabetes self-care behaviours. Diabet Med. 2006; 23(7): 795-802.

21. Balkrishan R, Rukmini R, Camacho FT, Huston AS, Murray F, Anderson R. Predictors of Medication Adherence and Associated Health Care Costs in an Older Population with Type 2 Diabetes Mellitus: A Longitudinal Cohort Study. Clin Ther. 2003; 25(11): 2958-71.22.

22. Lustman PJ, Williams MM, Sayuk GS, Nix BD, Clouse, RE. Factors influencing glycemic control in type 2 diabetes during acute- and Maintenance-Phase treatment of major depressive disorder with Bupropion. Diabetes Care. 2007; 30(3): 459 - 66.

23. Apóstolo JLA, Viveiros CSC, Nunes HIR, Domingues HRF. Incerteza na doença e motivação para o tratamento em diabéticos tipo 2. Rev Latinoam Enferm. 2007; 15(4): 575-82.

24. Zgibor JC, Songer TJ, Kelsey SF, Weissfeld J, Drash AL, Becker D, et al. The association of diabetes specialist care with health care practices and glycemic control in patients with type 1 diabetes: a cross-sectional analysis from the Pittsburgh epidemiology of diabetes complications study. Diabetes Care. 2000; 23(4): 472-6.

25. Lee H, Anh S, Kim Y. Self-care, Self-efficacy, and glycemic control of Koreans with diabetes mellitus. Asian Nurs Res. 2009; 3(3): 139-46.

26. Liebman J, Herffman D. Quality improvement in diabetes care using community health workers. Clin Diabetes. 2008; 26(2): 75-6.

27. Krapek K, King K, Warren SS, George KG, Caputo DA, Mihelich K, et al. Medication adherence and associeted hemoglobin A 1c in type 2 diabetes. Ann Pharmacother. 2004; 38(9): 1357-62.

28. Mateo J, Gil-Guillen VF, Mateo E, Orozco D, Carbayo JA, Merino J. Multifactorial approach and adherence to prescribed oral medications in patients with type 2 diabetes. Int J Clin Pract. 2006; 60:422-8.

29. Voss JD, Nadkarni MM, Schectman JM. The Clinical Health Economics System Simulation (CHESS): a teaching tool for systems- and practice-based learning. Acad Med. 2005; 80(2): 129-34.

30. Pladevall M, Williams LK, Potts LA, Divine G, Xi H, Lafata J.E. Clinical outcomes and adherence to medications measured by claims data in patients with diabetes. Diabetes Care. 2004; 27(12): 2800-05. 